\title{
Evaluation of a Modular Teaching Approach in Materials Science and Engineering
}

\author{
Ryan Manuel D. Guido* \\ Department of Earth and Space Sciences, Rizal Technological University, Mandaluyong City, Philippines \\ *Corresponding author: rmdguido@rtu.edu.ph
}

Received November 03, 2014; Revised November 23, 2014; Accepted November 27, 2014

\begin{abstract}
Material Science is an applied science concerned with the relationship between the structure and properties of materials. It is a discipline that enables the creation and application of materials in society. The challenge of this study is the use of the modular teaching approach in engineering materials. A standardized faculty student instructional module evaluation checklist that sought for the assessment of the learning objectives, evaluation of acceptability, effectiveness and the acquired skills in the module. The study shows that the instructional module in materials science and engineering are effective for students' knowledge adaptation and shows suitability to the level of the students and acceptability to the faculty evaluators. This reveals that the evaluators trusted that the module is very valuable to the course which makes students learning experience well stimulated.
\end{abstract}

Keywords: modular teaching approach, materials science and engineering, engineering science education, instructional materials, modular instruction

Cite This Article: Ryan Manuel D. Guido, "Evaluation of a Modular Teaching Approach in Materials Science and Engineering.” American Journal of Educational Research, vol. 2, no. 11 (2014): 1126-1130. doi: 10.12691/education-2-11-20.

\section{Introduction}

Material Science is an applied science concerned with the relationship between the structure and properties of materials. It involves the characterization of the physical and chemical properties id solid materials-metals and alloys, ceramics, magnetic materials, polymers, optical materials, semiconductors, superconductors, and composites, with the inclusion of its multidisciplinary studies in biochemical, industrial manufacturing processes and aerospace engineering.

Material Science or Engineering Materials or Material Science and Engineering comprise the study of materials from the macro to the atomic scale. It is concerned fundamentally with the effect of structure and chemistry on the properties of materials. The course extents and applications of these engineering materials to humanity.

Other Material Scientist in the forefront of biotechnology developed materials for the components of artificial joints, heart valves, and other replaceable body parts. Another focuses on military artillery by mounting highly caliber weaponry and aerospace technology.

It is a discipline that enables the creation and application of materials in society. Material Engineers or Material Scientist uses their knowledge to synthesize new materials with special properties. They are usually employed in industry or laboratories where they develop product-related technologies.

Teaching material science is one of the most challenging tasks. Material science instruction stresses the importance and understanding, and the ability to apply scientific models to completely realize the key specifications in technology structure of every new generation of development.

Teachers must adapt instruction to the student's level of knowledge and development, motivate them to learn, and manage their technical skills. Instructions and learning should be effective.

One way of maintaining the interest of the learners is to provide them with activities which they can perform individually, after being given the proper guidance, direction, instruction and encouragement by the teacher. This is the use of programmed instruction as a teaching tool. These programmed material claim to make learning interesting [24].

This study is anchored on a number of theories or ideas on the efficacy of instruction, however focused on the course material science. Since Philippine education recognizes a growing realization that it is best to provide students in a diverse learning techniques and strategies.

To be able to discourse the essentiality of instructional innovation and to acquiesce the rationality on the importance of instruction, this study envisioned the development of modular instructional in engineering materials, and determine its effect on student's performance.

Furthermore, to facilitate the inquiry into the effectiveness of modular instruction, the study aimed to determine whether the use of module in engineering materials would show positive results as compared to the lecture-discussion approach in teaching. 
The challenge of this study is the use of the modular teaching approach in engineering materials and to investigate its effects on the student's achievement. It is worth chasing research because it is the pursuit of construction of a module, measurement and evaluation, and the effects of this modular instruction in the cognitive behavior of the students.

This study is anchored on the invaluable educational psychology researches that build the framework in the evaluation of the cognitive ability, behavior and attitudes of the learners.

A concrete basis in learning theory is a vital element in the application of modular instruction. However, there are plenty of theories for the design of a modular instruction based learning. With this, the researcher adopts the use of an eclectic approach as learning theory to the use of the modular instruction so that pedagogical principles from different learning theory can support the methodology.

\section{Literature Review}

\subsection{Modular Instruction}

Modular instruction is one of the latest innovations in the educational system. This innovation in the modular approach contains a series of activities each of which start with teaching instructions addressed to the learners, explanation, exercises and generalizations.

A module is defined as a self-contained, independent unit of a planned series of learning activities designed to help the student accomplish certain well-defined objectives. The learner is able to proceed at this own rate and recycle if necessary.

Modules emphasized analysis and application of concepts and techniques and gives concrete style of concepts. It also provides active participation of students in responding and a wait to meet areas of individual interest and helps the teacher extend more individualized instruction in school and at home.

With this, the learner is able to proceed at his own rate, choose his own learning mode, select along a variety of topics, identify his strengths and weaknesses, and recycle if necessary. Ideally, modules should include pre-test, objective, criteria for success, instructional activities, a post test, and remedial instruction and/or reinforcement.

Modular instruction is based on the psychological principle-learning by doing. The learner works by itself and verifies the correctness of his answers by comparing it with the correct one. It also gives the students some provision whereby the student can obtain an immediate feedback.

Modular instruction promises a more efficient mass education by offering more effective individual instruction at a time when a teacher is faced with a problem of producing learning in a large group all at the same time. It is a technique of self-instruction that involves the presentation of instructional materials to demonstrate their skills and comprehension [5].

The principles and purpose of modular instruction, its advantages for both students and instructors, and a comparison between the conventional and modular approach are presented. Present evidence suggests that modular instruction meets the needs of today's students more learning and the content.
Instructional materials can serve as learning materials for both students and teachers. They can serve a primary source of science content, present specific views about the nature of scientific practices, and how scientific knowledge is developed. Materials can also serve as a primary influence on how teachers should teach science [20].

For the proper implementation of any school curriculum, textbooks become part and parcel of the education system. Especially, in developing countries, it has been a regular practice to consider textbooks as the major source of the teaching learning process to be undertaken in schools. [17].

There is also the possibility that reviewers do not have enough expertise to understand, how to analyze the text with respect to cognitive development. The results point out that merely providing the main contents of the curriculum to the authors does not ensure coverage of the topics demanded in the curriculum.

The modules in the principles and methods of teaching include lessons and topics which meet the requirements of authorities in teacher education. The contents of the modules reflect the most important aspects of what is being taught. The modules provide evaluation activities which relate to the content and objectives of the lessons; however, there is no provision for pretest and posttest activities in each module. There is highly significant difference between the students' and the teachers' assessment of the characteristics of the modules with the teachers' assessment higher than that of the students [16].

An evaluated and tried out environmental outdoor education module for the use of students of St. Scholastica College found out that the majority of the students' comments and responses to the guide questions and personal insights were positive. The remarks and suggestions were sufficient reasons for considering the modules suitable and purposeful. She concluded that the module was able to a great extent to meet the criteria set in terms of content, instructional characteristics and effectiveness [23].

\subsection{Instructional Materials}

The use of self-instructional materials are particularly beneficial as a strategy in introducing basic information to an entire class, freeing the lecture discussion hours for more "discussions" and less "lecture", an enrichment activity for talented students; a strategy to make-up for a student who has been absent and a strategy for a student in need of remedial lectures [16].

It is explained that instructional materials offer the best means by which a teacher can provide direction in her students' daily search for new understanding and verifications [22].

The use of modules as a learning material is no longer new in the field of education especially in the tertiary level. This teaching-learning material is characterized by smallstep, sequential and concept-and/or skill-oriented presentation of a unit of learning [16].

A self-instructional module is a self-contained, independent unit of instruction prepared for the purpose of attaining defined instructional objectives. It is characteristically self-directing since it includes instruction on how the various investigations will be pursued [22]. 
The preparation of self-instructional modules includes careful analysis of the course plan or syllabus, preparing preliminaries and designing of the learning activities. The design of the learning activities includes the objectives, directions, pretest and key, activity proper, self-evaluation exercises and posttests [16].

It is described that modular instruction provides the basis for a close interaction between the learner and the subject matter, that the learner is called upon to respond actively in the interaction with an instructional program, and that the rate at which the interaction proceeds are governed individually by each learner's response [14].

The advantages offers to the teacher who uses the modular approach. These are: it provides the opportunity for organizing numerous sequences to reflect special interests of the teacher and students; it allows the teacher to focus on the deficiencies of students in the subject matter; it serves to eliminate the necessity of covering the subject matter already known to students. With the use of modules, the progress of a student is assessed and the routine aspect of instruction is reduced giving the teacher a chance to enjoy her personal contact with the students [13].

The developed and evaluated instructional materials for the enhancement of listening skills among freshman students of St. Michael College of Laguna concluded that students need instructional materials that will help them realize and make sure of their internal language resources to be able to attend to and appreciate listening [19].

The proposed instructional modules in developing computational skills in College Algebra. She concluded that the proposed instructional modules had titles, instruction to the learners, rationale, objectives, and pretest with answer key, worksheet assignment, and progress check with answer key and post-test with answer key [3].

A study that showed results that there was a significant increase in the pre-test and post-test results of the students when the instructional material was introduced in the class [12].

The instructional modules form an important educational innovation and teaching technique. Aside from proposing a solution to the problems of teaching instruction, modules are more efficient mass education by giving more effective individual instruction [1].

Another study reveals that the developed instructional materials for interactive learning are useful and beneficial for the improvement of the students' communication skills. The instructional materials provide content which are suitable, effective and which cater to different learning styles and preferences and which promote cooperative learning as perceive by the teacher experts who tries out the materials and the number of students who used the material [18].

Instructional materials are useful in teaching college basic mathematics. Instructional materials with manipulated activities are helpful in developing basic concepts of mathematics [10].

\subsection{Assessment of Engineering Science Education}

The ability of science teacher to organize classrooms, manage behavior or their students and use instructional materials effectively in their teaching is critical to achieving positive educational outcomes. Proper evaluation of science teacher preparation and use of instructional materials reduces classroom problems [6,9].

There is also a support on the usefulness of assessment that it compliments students' learning efforts and increases the likelihood that students learn, retain, and transfer what is being taught [15].

Research on students' academic achievement has generally taken the form of finding human or environmental variables which correlate with higher achievement and which can be used as predictors of achievement, some of which variables identified is individual differences [4].

A central challenge in science education is the development of coherent educational models that integrate central ideas and practices within and across disciplines.

Educational research shows that promoting metacognition in the science classroom prompts students to refine their ideas about scientific concepts and improves their problem solving success [21].

Teaching science is one of the most important parts of education. The research was made to identify the effects of the educational factors on the academic performance of the university students [2].

Research on approaches to learning refers mainly to organized studying or organized effort in studying, which emphasizes good time management, self-regulation and effort in studying rather than of the motivation to achieve $[7,8]$.

The instructional cycle and intensive coaching enabled most instructors to change their practices, shift their focus from teaching to learning, and enhance their knowledge of student learning difficulties [11].

The development of instructional configurations centered on learning progressions must be based on the fundamental ideas and understanding of the hierarchy of cognitive and educational domain in the nature of science literature. Constructing knowledge and developing assessment and evaluation is a consistent process for the development of students' level that would build incremental grade modifications.

\section{Methodology}

\subsection{Research Methods}

The research indicates the inherent characteristics with the gathering of data. It purports and presents facts concerning the Evaluation of Modular Approach in Materials Science and Engineering. It also involves in the analysis on the assessment of the result of data gathered from questionnaires distributed to the respondents. It gives significance to the quality and standing facts.

A survey technique causal-comparative research design describes conditions that already exist. It shows to understand the cause and effect of the research as it determines the effect of the instructional module in materials science and engineering as the cause of the student achievement. The study also involves selecting the characteristics of the study and uses the fastest way of getting their opinions, reaction, responses to the instrument in the module evaluation checklist for the faculty and student. 


\subsection{Participants of the Study}

The samples are 86 engineering students who were enrolled during the 2014 summer class in the fundamentals of materials science and engineering and 4 faculty respondents who are teaching the said course during the 2014 summer class at the Rizal Technological University.

\subsection{Instrument}

The instrument used standardized Module Evaluation Checklist to assess the learning objectives, evaluation of acceptability, effectiveness and the acquired skills in the module. It has five degrees of intensity with weights of 5 being the highest and 1 being the lowest rating. The scale of the statistical value adopted to assess the aspects are as follows:

$\begin{array}{lll}\text { Weighted } & \text { Arbitrary } & \text { Verbal Interpretation } \\ \text { Mean } & \text { Value } & \\ 4.51-5.00 & 5 & \text { Excellent } \\ 3.51-4.50 & 4 & \text { Very Satisfactory } \\ 2.51-3.50 & 3 & \text { Satisfactory } \\ 1.51-2.50 & 2 & \text { Fair } \\ 1.00-1.50 & 1 & \text { Poor }\end{array}$

\subsection{Research Procedure}

The evaluation of the faculty and students towards the instructional module in materials science and engineering. The assessment of the 86 engineering students and 4 faculty responses towards the subject were given the evaluation form during their fundamentals of materials science and engineering class to identify their assessment towards the instructional material. This was done at Rizal Technological University in the College of Engineering and Industrial Technology taking the fundamentals of materials science and engineering subject during the 2014 summer class.

\subsection{Data Analysis}

Faculty and student responses to the instrument were coded based on the 5-point Likert Scale determination per criteria so that the higher scores embodied more positive responses. Using the SPSS program, a one-way analysis of variance (ANOVA) was conducted to determine the significant difference in the evaluation of the students per department, and between faculty and students. Pearson's Product Moment Correlation to determine the significant relationship between the faculty and student responses in the evaluation of the module.

\section{Results and Discussion}

\subsection{Significant Differences in the Evaluation of the Students in the Effectiveness of the Module}

Table 1 shows that the tabular value of 3.229583 is greater than the computed value of 1.481448 . Based on grouping of their blocks, this indicates that it failed to reject the null hypothesis and therefore concludes that there is no significant difference in the evaluation of the students in the effectiveness of the module.
Table 1. Analysis of Variance on the Students' Evaluation of the Effectiveness of the Module

\begin{tabular}{|l|c|c|c|c|c|c|}
\hline ANOVA & & & & & & \\
\hline Source of Variation & $S S$ & $d f$ & $M S$ & $F$ & P-value & F crit \\
\hline Between Groups & 0.181 & 8 & 0.0226 & 1.4814 & 0.284 & 3.229 \\
\hline Within Groups & 0.137 & 9 & 0.0152 & & & \\
\hline Total & 0.318 & 17 & & & & \\
\hline
\end{tabular}

This reveals that student assessment in the module significantly stressed out that the use of the module as a teaching tool claim to be more adequate than the traditional or conventional teaching with respect to the quality of learning as it helped them improve their understanding of the subject matter.

The result of the study accompanied in the study that the use of self-instructional materials are particularly beneficial as a strategy in introducing basic information to an entire class [16].

\subsection{Significant Differences in the Evaluation of the Faculty and Students in the Effectiveness of the Module}

Table 2. Analysis of Variance on the Faculty and Students' Evaluation of the Effectiveness of the Module

\begin{tabular}{|l|c|c|c|c|c|c|}
\hline ANOVA & & & & & & \\
\hline Source of Variation & $S S$ & $d f$ & $M S$ & $F$ & P-value & F crit \\
\hline Between Groups & 0.010 & 1 & 0.0106 & 0.4150 & 0.528 & 4.493 \\
\hline Within Groups & 0.411 & 16 & 0.0257 & & & \\
\hline Total & 0.422 & 17 & & & & \\
\hline
\end{tabular}

Level of significance at 0.05

Table 2 reveals the tabular value of 4.493998 is greater than the computed value of 0.415049 . This indicates that it failed to reject the null hypothesis and therefore concludes that there is no significant difference in the Faculty and Student evaluation of the effectiveness of the module.

This indicates that it merits the modular teaching approach using the instructional module in material science and engineering as an effective strategy to improve learning capability by individual performance, after given the proper guidance, administration and support of the teacher.

This result is associated with the studies that the ability of science teacher to use instructional materials effectively in teaching is critical to achieving positive educational outcomes. Proper evaluation of science teacher preparation and use of instructional materials reduces classroom problems [6,9].

\subsection{Significant Relationship between the Faculty and Students' Evaluation of the Effectiveness of the Module}

Table 3. Pearson Product Moment Correlation of the Faculty and Students' Evaluation of the Effectiveness of the Module

\begin{tabular}{|c|c|c|}
\hline & Student & Faculty \\
\hline Student & 1 & \\
\hline Faculty & 0.22491 & 1 \\
\hline
\end{tabular}

Table 3 shows the correlation of the Faculty and Students' evaluation on the effectiveness of the module. There is a marked positive relationship between the 
Faculty and Students' evaluation. For the relationship between the Faculty and Students' evaluation, $r=0.22491$. The relationship is positive; as the student evaluation increases, the faculty evaluation also increases. The coefficient of determination is $\mathrm{r}^{2}=0.0505$, this presents the student evaluation improves the prediction of the rated factors by $5 \%$. The faculty evaluation expresses $5 \%$ of the variation in the evaluation of the effectiveness of the module. The relationship is significant at $\alpha=0.05, t_{t v}=$ $0.2126<t_{c v}=2.1154$.

\section{Conclusion}

The findings of the study show that the instructional module in materials science and engineering are effective for students' knowledge adaptation and shows suitability to the level of the students and acceptability to the faculty evaluators. This reveals that the evaluators trusted that the module is very valuable to the course which makes students learning experience well stimulated. The instructional module affirms that the realization of appropriateness, development and comprehension of competency of the module are well identified as it helped students' progress in cognitive abilities and understanding of the concepts.

There is no significant difference in the evaluation between the student respondents, and between the faculty and student respondents in the effectiveness of the module. Moreover, there is a significant positive relationship between the faculty and student respondents' evaluation. The instructional module is found to be effective in teaching and stimulates the critical thinking in a coherent academic pursuit as it enhances students' understanding and critical thinking.

\section{Recommendation}

The relevance of the self-assessment per chapter and the mastery test in the instructional module may be utilized for the determination of the academic achievement of the students.

The chapters may incorporate additional topics that are relevant to the course. This is a considerable effect of the emerging technologies in the branches of material science and engineering.

The module may be validated by more evaluators and may be utilized for a large group of students to be able to apprehend a more valid expression of evaluators through the authors' validation process.

Further, researchers may focus on the educational outcomes of the students in the course which form part of the engineering sciences board examination.

Likewise, there is also a need to further develop the module to be able to achieve a caliber educational perspective.

\section{References}

[1] Acelejado, M. The Modular Teaching Approach in College Algebra: An Alternative to Improving the Learner's Achievement, Persistence, and Confidence in Mathematics. 2006. DLSU, Philippines.

[2] Alavi, H., \&Hoseini, A. The Effects of Educational Factors on the Academic Performance of the University Students in Chemistry. Chemical Education Journal. 2009 (13) 2, 13-14.

[3] Aquino-Danganan, A. Development and Validation of a Module in Developing Computational Skills in College Algebra. Tarlac State University. 2001.

[4] Bassey. Cognitive Style, Secondary Schools Students' Attitude and Academic Performance in Chemistryin akwaimbo state - Nigeria. 2006.

[5] Deterline, W. An Introduction to Programmed Instruction. New Jersey: Prentice Hall Inc. 1982.

[6] Emmer, E. \& Stough L. Classroom Management: A Critical Part of Educational Psychology, with Implications for Teacher Education. Educational Psychologist. 2003.

[7] Entwistle, N., \& McCune, V. The Conceptual Bases of Study Strategy Inventories. Educational Psychological Reviews, 16, 245325. 2004.

[8] Entwistle, N., \& Peterson, E. Conceptions of Learning and Knowledge in Higher Education: Relationships with Study Behavior and Influences of Learning Environments. International Journal of Educational Research, 41, 407-428. 2005

[9] Flick, L. \& Bell, R. Preparing tomorrow's Science Teachers to use Technology: Guidelines for Science Educators. Contemporary Issues in Technology and Teacher Education, 1 (1), 39-60. 2005.

[10] Galanida, C. Development and Validation of Instructional Materials for Basic Mathematics. Philippine Normal University. 2006.

[11] Gallos, M., Van Den Berg, E., \& Treagust, D. The Effect of Integrated Courses and Faculty Development: Experiences of a University Chemistry Department in the Philippines. International Journal of Science Education. 27 (8), 985-1006. 2005.

[12] Garillos, M. N. T. Development and Validation of Instructional Module in Biology for Second Year High School. TVC-Sta. Teresa National High School. 2012.

[13] Greager, J. And Murray, D. The Use of Modules in College Teaching. Washington, D.C: Nichols Publishing Co., Inc. 1991.

[14] Hughes, J. L. Programmed Instruction for Schools and Industry. Chicago: Research Association, Inc. 1992.

[15] Johnson, D. W., \& Johnson, R. T. Meaningful Assessment: A Manageable and Cooperative Process. Boston: Allyn and Bacon. 2002.

[16] Macarandang, M. A. Evaluation of a Proposed Set of Modules in Principles and Method of Teaching. E-International Scientific Research Journal, 1, 1-24. 2009.

[17] Mahmood, K. Textbook Evaluation in Pakistan: Issue of Conformity to the National Curriculum Guidelines. Bulletin of Education and Research, 32, 15-36. 2010.

[18] May-as, A. D. Development of Instructional Materials for Interactive Learning. 2006.

[19] Receno, C. N. Development of Instructional Materials for the Enhancement of the Listening Skills among Freshmen College Students of SMCL. PNU. 2001.

[20] Reiser, B. J., et al. Design Strategies for Developing Science Instructional Materials. National Association for Research in Science Teaching. 2003.

[21] Rickey, D., \& Stacy, A. The Role of Metacognition in Learning Chemistry. Journal of Chemical Education. 77 (7), 915. 2002.

[22] Salandanan, G. Teacher Education Journal. Quezon City: Katha Publishing Co., Inc. 2001.

[23] Samonte, M. C. L. Development, Evaluation and Try-out of an Environmental Outdoor Education Module. PNU. 2004.

[24] Skinner, B. Science and Human Behavior. New York: The McMillan Co. 1983. 